\title{
The longstanding challenge of the nanocrystallization of 1,3,5-trinitroperhydro-1,3,5-triazine (RDX)
}

\author{
Florent Pessina* and Denis Spitzer
}

\author{
Review \\ Address: \\ NS3E, UMR 3208 ISL-CNRS-Unistra, Institut franco-allemand de \\ recherches de Saint-Louis (ISL), 5 rue du Général Cassagnou, \\ F-68301 St. Louis, France \\ Email: \\ Florent Pessina* - fpessina@unistra.fr \\ ${ }^{*}$ Corresponding author \\ Keywords: \\ crystallization; nanoparticles; RDX; review; submicrometer; \\ 1,3,5-trinitroperhydro-1,3,5-triazine
}

\author{
Beilstein J. Nanotechnol. 2017, 8, 452-466. \\ doi:10.3762/bjnano.8.49 \\ Received: 14 September 2016 \\ Accepted: 01 February 2017 \\ Published: 17 February 2017 \\ This article is part of the Thematic Series "Self-assembly of \\ nanostructures and nanomaterials II". \\ Guest Editor: I. Berbezier \\ (C) 2017 Pessina and Spitzer; licensee Beilstein-Institut. \\ License and terms: see end of document.
}

Open Access

\begin{abstract}
Research efforts for realizing safer and higher performance energetic materials are continuing unabated all over the globe. While the thermites - pyrotechnic compositions of an oxide and a metal - have been finely tailored thanks to progress in other sectors, organic high explosives are still stagnating. The most symptomatic example is the longstanding challenge of the nanocrystallization of 1,3,5-trinitroperhydro-1,3,5-triazine (RDX). Recent advances in crystallization processes and milling technology mark the beginning of a new area which will hopefully lead the pyroelectric industry to finally embrace nanotechnology. This work reviews the previous and current techniques used to crystallize RDX at a submicrometer scale or smaller. Several key points are highlighted then discussed, such as the smallest particle size and its morphology, and the scale-up capacity and the versatility of the process.
\end{abstract}

\section{Review \\ Introduction}

While nanotechnology has spread to nearly all other sub-fields of material science, the pyrotechnic community has struggled to produce very fine particles of organic explosives. Beside the technical considerations, scientists are also striving to convince the quite conservative military industry of the added value of energetic nanomaterials. While the interest in nanoparticles has been recently highlighted, companies continue with process optimization [1] and observe the technological breakthroughs of the last decades with caution. As a consequence, the innovation has been mainly focused on the synthesis and prediction of new molecules such as 1,3,3-trinitroazetidine (TNAZ), 2,4,6,8,10,12-hexanitro-2,4,6,8,10,12-hexaazaisowurtzitane (CL-20), octanitrocubane (ONC), 1,1-diamino-2,2-dinitroethene (FOX7), ammonium dinitramide (ADN), and 5-nitro1,2,4-triazol-3-one (NTO). These new materials aim to achieve higher density, to increase the processability and to attain insensitive munition (IM) characteristics; however, IM properties actually rely on the whole physics-chemistry of the system. 
Therefore, the development of powders with controlled particle size and morphology and well-defined surface chemistry is largely unexplored for energetic materials at the sub-micrometer scale and smaller. The criteria that are advantageous for new energetic materials include the following:

- high decomposition temperature

- low sensitivity

- no phase transitions under compression or depression

- no autocatalytic decomposition

- no voids from solvents or gas

- mechanical behavior independent from temperature

- good availability/cost ratio

- easy processing

The compression of gaseous inclusions, cavities and voids, deformation, frictional heating, intercrystalline shearing and spark discharge (electrostatic discharge (ESD)) are initiation processes which can cause areas of an energetic material to heat up to several hundred Kelvin. These areas are called hot spots and are deflagration or detonation origins if they reach a critical temperature. Tarver [2] calculated the critical temperature for octahydro-1,3,5,7-tetranitro-1,3,5,7-tetrazocine (HMX) of different sized hot spots. For a $2 \mu \mathrm{m}$ diameter hot spot he calculated a critical temperature of $985 \mathrm{~K}$, whereas the critical temperature for a $0.2 \mu \mathrm{m}$ hot spot already rises to $1162 \mathrm{~K}$.

Risse [3] measured a noticeable desensitization towards initiation by friction and electrostatic discharge for nanostructured 1,3,5-trinitroperhydro-1,3,5-triazine (RDX) crystallized by spray flash evaporation (SFE), compared to the raw material (Table 1). The noticeably lower sensitivity towards friction can be based on the self-lubricating effect, as small particles will tend to occupy small interstices instead of breaking. Sensitivity measurements were also performed on hexolite, which showed a clear desensitization of the nanostructured explosive (Table 2).

$\begin{aligned} & \text { Table 1: Sensitivity towards impact, friction and ESD of micrometer- } \\
& \text { sized and nanostructured RDX (n-RDX) [3]. }\end{aligned}$
\begin{tabular}{lccc} 
Impact & Friction & ESD \\
RDX & {$[\mathrm{J}]$} & {$[\mathrm{N}]$} & {$[\mathrm{mJ}]$} \\
\hline M5 (raw material) & $>3.52$ & 160 & 120 \\
nanostructured RDX & $>3.52$ & $>360$ & 270 \\
\hline
\end{tabular}

Using a sonocrystallization process, Bayat and Zeynali [4] succeeded in the preparation of $n-2,4,6,8,10,12$-hexanitro2,4,6,8,10,12-hexaazaisowurtzitane (n-CL-20), which was less sensitive towards friction, impact and electrostatic discharge (Table 3).
Table 2: Comparison of the sensitivity levels of micrometer-sized hexolite with those of a nanometer-sized hexolite (n-hexolite) [3].

\begin{tabular}{lccc} 
Hexolite & $\begin{array}{c}\text { Impact } \\
{[\mathrm{J}]}\end{array}$ & $\begin{array}{c}\text { Friction } \\
{[\mathrm{N}]}\end{array}$ & $\begin{array}{c}\text { ESD } \\
{[\mathrm{mJ}]}\end{array}$ \\
\hline micrometer & 6 & 54 & 353.6 \\
nanometer & 25.06 & 72 & 436.6
\end{tabular}

Table 3: Comparison of the sensitivity levels of micrometer and nanometer-sized CL-20 [4].

\begin{tabular}{cccc}
$\begin{array}{c}\text { Particle size } \\
{[\mu \mathrm{L}]}\end{array}$ & $\begin{array}{c}\text { Impact } \\
{[\mathrm{cm}]}\end{array}$ & $\begin{array}{c}\text { Friction } \\
{[\mathrm{kg}]}\end{array}$ & $\begin{array}{c}\text { ESD } \\
{[\mathrm{J}]}\end{array}$ \\
\hline 15 & 25 & 6.4 & 45 \\
0.095 & 55 & no reaction & 60
\end{tabular}

Klapötke has often experienced the influence of particle size on ESD, when stating for example "the finer the powder of a particular (note from authors: RDX) sample is, the higher the ESD sensitivity values are" [5]. However, this trend is not always observed. Crystallized from rapid expansion of supercritical solutions (RESS), several nanometer-scale RDX (n-RDX) lots have been tested by Stepanov et al. [6]; while both $500 \mathrm{~nm}$ and $200 \mathrm{~nm}$ diameter RDX are less sensitive toward impact than milled $4 \mu \mathrm{m}$ RDX, the $200 \mathrm{~nm}$ diameter lot is substantially more sensitive than the $500 \mathrm{~nm}$ one. As it can be seen in Figure 1, the minimum sensitivity to impact is confirmed when coating the powders with a binder; however, that confirmation might reveal that the trend is more due to the intrinsic bulk properties of the particles instead of their surface. Klaumünzer et al. [7] investigated the sensitization of n-RDX against impact and strongly reaffirmed that the generalization of a direct

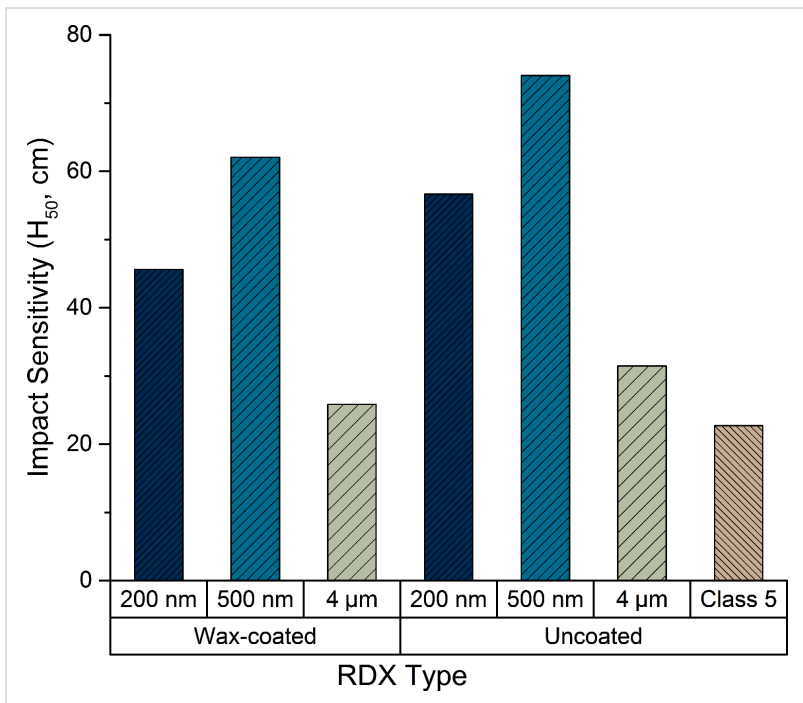

Figure 1: Impact sensitivity of RDX as a function of RDX type and particle diameter, adapted from [6]. 
link between smaller particle and lower impact sensitivity - as seen many times in the literature - should be more forcefully addressed.

Beside safety, other improvements can emerge from materials prepared on the nanoscale. The critical diameter, tunable detonation velocity, delay before the detonation steady state, etc. may be improved by the drastic grain size reduction. Energetic nanocomposites are also promising materials improved by a more intimate mixing. Liu et al. [8] showed that detonation velocities of PBX composition from their milled n-RDX and n-HMX materials are slightly better while being significantly safer. The burning rate of nitrocellulose was also improved by Zhang and Weeks [9] due to the formation of sub-micrometer spheres. Recently, Comet et al. [10] proved that energetic nanocomposites can easily replace the hazardous primary explosives to initiate a secondary explosive: $500 \mathrm{~nm}$ diameter n-RDX from SFE was mixed with a nanoscale thermite to initiate the detonation of PETN. The flame propagation velocity (FPV) of composites made of $n-\mathrm{WO}_{3} / \mathrm{n}-\mathrm{Al} / \mathrm{n}-\mathrm{RDX}$ can be tuned from 0.2 to $3.5 \mathrm{~km} / \mathrm{s}$ through their explosive content. Under the same conditions, $\mathrm{n}-\mathrm{WO}_{3} / \mathrm{n}-\mathrm{Al}$ with $\mu$-RDX exhibit unstable regimes from 187 to $733 \mathrm{~m} / \mathrm{s}$, whereas the $\mathrm{n}-\mathrm{WO}_{3} / \mathrm{n}-\mathrm{Al} / \mathrm{n}-\mathrm{RDX}$ composite deflagrates at a constant velocity of $2529 \mathrm{~m} / \mathrm{s}$. Those and other unpublished results from our laboratory confirm the drastic reduction of the critical diameter with the decrease of particle size.

1,3,5-Trinitroperhydro-1,3,5-triazine is also found under the following descriptors: cyclo-1,3,5-trimethylene-2,4,6-trinitramine, 1,3,5-trinitrohexahydro-s-triazine, cyclotrimethylenetrinitramine, hexahydro-1,3,5-trinitro-s-triazine, trimethylenetrinitramine, T4, cyclonite, hexogene and RDX. The most common and widely accepted one is the acronym RDX and is the one used in this present work. With nitro groups and a triazine cycle, it is chemically similar to many organic explosives and thus a good representative sample. Additionally, although it was created in the 1930s, RDX is still widely used for civilian and military applications, reinforcing its interest in industrial and scientific studies. Therefore, RDX has been used over the years as a reference for crystallization experiments, aiming to reduce the size of energetic organic crystals below a micrometer. Many crystallization processes inspired from other fields of chemistry, such as polymer crystallization, have been applied but only a few resulted in a significant size reduction.

The present review aims to fairly depict all the crystallization processes used on the same material, RDX, and the limitations encountered. The smallest particle size is of interest and will be offset against the maturity of the technology. The interest for a process can be also expressed according to its versatility and its ability to process continuously as per industrial standards. Such key points are further discussed in the conclusion. The classification suggested here is based on the final state of the particle formation. If a significant additional step is required to dry the particles, which is often because the crystallization occurs in a liquid that does not simultaneously evaporate or is not in a supercritical state, the technique is classified as a wet production method. There is only one notable exception, the aerosol solvent extraction system (ASES), sorted among the supercritical processes for a better understanding. Melting and milling processes for producing sub-micrometer energetic materials require one or more additional liquids, therefore these techniques are classified as wet methods.

\section{Wet production methods Crystallization from solution}

Crystallization from solution has been studied but also used at the industrial scale for centuries. From solution, hydraulic processes can be easily monitored, controlled, and continuously operated. Therefore, substantial efforts have been made to scale the crystallization of energetic particles with existing technologies.

Depending on the creation of supersaturation, distinctions are made between cooling, evaporation, vacuum cooling, drowning-out and reaction crystallization. The study of the solubility of the compound is the key to determine which crystallization process can be used. For instance, if the solubility is not very temperature dependent, evaporation will be more effective than cooling. To our knowledge, no consistent study of the behavior of the solubility of RDX has been made. Fedoroff and Sheffield [11] indicate that the RDX solubility in acetone is reduced four times by cooling from 60 to $0{ }^{\circ} \mathrm{C}$. Pant et al. [12] used all standard techniques available to recrystallize RDX into sub-micrometer crystals in a beaker. The smallest size was obtained when the antisolvent was added to a cooled, highly supersaturated solution, while applying ultrasonication and stirring. Achieving a high level of supersaturation results in a higher nucleation rate, but aggregation increases rapidly. For this solvent/compound system, they produced smaller particles and reduced the agglomeration by sonication and the particles were finally obtained by drying. This method may be suitable for industry, however, the minimum size obtained was only $850 \mathrm{~nm}$ under tough conditions, with a yield of $60 \%$, resulting in rod-shaped crystals. Such morphology must be avoided due the well-established sensitization for materials with a high length-to-width ratio [13-15]. Increasing roughness due to surface defects also sensitizes the energetic materials.

Kumar et al. [16] succeeded in producing finer RDX particles by quickly injecting a very small volume $(100 \mu \mathrm{L})$ of RDX dis- 
solved in acetone into ultrapure water. The smallest mean particle size was $38 \mathrm{~nm}$ as determined by scanning electron microscopy (SEM) for the highest temperature $\left(70^{\circ} \mathrm{C}\right)$ and lowest concentration of RDX in acetone $(5 \mathrm{mM})$. It is worth mentioning that dynamic light scattering (DLS) measurements were found to be not reliable when compared to SEM analysis, which can be explained by the lack of surfactant to stabilize the colloid. This technique was also applied on HMX [17] with a particle size around $30 \mathrm{~nm}$ and the same conclusions were drawn.

Bayat et al. [18], through an optimization of the microemulsion process, crystallized $80 \mathrm{~nm}$ plate-like $\beta$-CL-20 particles. The severe agglomeration and plate-like morphology could be due to the freeze drying and washing of the microemulsion. Gao et al. [19] recrystallized 1,1-diamino-2,2-dinitroethene (FOX7) in ethyl alcohol down to the sub-micrometer range. SEM pictures show an irregular plate-like morphology and therefore highlight the inconsistency of the unique mean particle size of $340 \mathrm{~nm}$ claimed. The particles also exhibit a certain degree of agglomeration which can be explained again by the pool of surfactant and the air-drying method used.

Luo et al. [20] reached an impressive mean diameter of $30 \mathrm{~nm}$ of RDX. They used an unusual technique where RDX is dispersed in bacterial cellulose. The smallest particle size was obtained with a $71 \%$ RDX/gelatine mixture. However, increasing the content of RDX leads to an increase in the particle size and the maximum RDX loading tested was $91 \%$ resulting in a mean particle diameter of $50 \mathrm{~nm}$. The sensitivity of this composite towards impact and friction was reduced by two times, therefore questioning the reactivity. Nevertheless, further efforts were made to replace the bacterial cellulose with an energetic matrix.

Crystallization in solution allows the formation of large crystals by growth, thus allowing more parametric studies regarding the influence of solvents. For instance, one work [21] has studied the importance of temperature and supersaturation for the crystallization for HMX in $\gamma$-butyrolactone, revealing that low temperature and highly supersaturated solutions tend to increase the defects in HMX crystals.

\section{Solvent substitution using reverse micelles}

Dabin et al. [22] have developed an ingenious method to prepare nanometer-scale RDX using a simple technique. The crystallization is triggered by a solvent substitution, and the nanometer scale material is obtained by restricting the reactor volume using reverse micelles. NaAOT (sodium 1,4-bis(2ethylhexoxy)-1,4-dioxobutane-2-sulfonate) with isooctane was used to form reverse micelles. Then RDX in dimethylformamide (DMF) is added to one solution containing these micelles, and water to another solution of micelles. Both are finally mixed together to form the n-RDX with a diameter of 70 to $100 \mathrm{~nm}$. However, the nanoparticles produced from this elegant solution exhibit an undesired rod-like morphology.

\section{Sol-gel}

Energetic materials processed by the sol-gel method are desensitized by being embedded in a matrix, usually a silica one. Developed by Gash et al. [23] and Tillotson et al. [24,25], the silica explosive gels are prepared by dissolving the energetic compound, the silica precursor and a catalyst in a co-solvent. After the gelification, an antisolvent of the explosive is injected to replace the solvent in the pores and precipitate the explosives in the silica matrix. By drying with heating or at low pressure, a xerogel with higher density is obtained. If supercritical $\mathrm{CO}_{2}$ is used to extract the solvent, an aerogel with low density is formed. Therefore, the nanostructured nature of the explosive comes from the porous matrix: cavities of mesoporous gels are 2 to $50 \mathrm{~nm}$ large and less than $2 \mathrm{~nm}$ for microporous gels. Macroporous materials have pore diameters greater than $50 \mathrm{~nm}$ [26].

An RDX/resorcinol formaldehyde (RF) nanocomposite has been synthesized [27] where $38 \mathrm{~nm}$ RDX crystallized in an RF aerogel matrix with a surface area of $551.5 \mathrm{~m}^{2} / \mathrm{g}$ (measurement taken without RDX). Wuillaume et al. [28] trapped ammonium perchlorate (AP) and RDX in a mesoporous low-density energetic organogel. During the impact test, a negligible decrease of sensitivity was measured: 75 wt \% RDX nanogels and macrogels had the same sensitivity and the $90 \mathrm{wt} \%$ nanogels are even more sensitive than their macroscopic counterparts. When compared to pure RDX, the $90 \mathrm{wt} \%$ nanogels are not desensitized. However, small scale gap tests (SSGTs) preformed on pressed gels (95\% TMD) revealed an improvement of the sensitivity for the $90 \mathrm{wt} \%$ RDX nanoformulation. The nanogel exhibits an uncommon microstructure of sheets, with micrometer-sized particles potentially formed by primary nanoparticles. The lack of desensitization in the loose powder may be explained by the sensitization by the sheet-like shape counteracted by the presence of the gel coating each nanoparticle.

Li et al. [29] used a better energetic matrix, GAP, with a maximum of $40 \mathrm{wt} \%$ RDX. They noticed a lower sensitivity than the physical mix. However, the claimed nanometer diameter is only deduced from the porosity without RDX and from X-ray diffraction (XRD) patterns which only give the mean coherence length. They also created NC-RDX-AP nanocomposites using a technique similar to sol-gel [30]. The matrix is the NC itself solidified by micrometer-sized AP crystals and crosslinked with toluene diisocyanate (TDI) and dibutyltin dilaurate (DBTDL), whereas RDX is dissolved in acetone inside that 
template. The gel and the crystallization of RDX is triggered by supercritical $\mathrm{CO}_{2}$ drying. Even if the sensitivity and the density were not improved, the increase of the heat of explosion measured and the originality of the approach make the formation of a nanocomposite based entirely on energetic materials through chemical binding promising.

\section{Melting}

Many high energetic materials degrade very close to their melting point. Therefore, only a few such as 2,4,6-trinitrotoluene (TNT) or TNB can be used in the molten state since the melting temperature is at least $100{ }^{\circ} \mathrm{C}$ away from the exothermic decomposition. The melt-cast process of TNT-based compositions has been used for shaping charges or loading them into ammunitions since World War I. Crystallization from an emulsified molten explosive is an innovative technique used by Anniyappan et al. [31]. 2,4,6-triazido-1,3,5-triazine (or cyanuric triazide, CTA) has been processed at $95{ }^{\circ} \mathrm{C}$ to crystallize as micrometer-sized agglomerates. CTA is a promising primary explosive compliant with the new REACH legislation [32] forbidding the use of heavy-metal-based materials. Further investigation with surfactants might lead to smaller particles by counteracting the high viscosity of molten droplets.

\section{Milling}

Redner et al. [33] developed a batch wet-milling process, producing sub-micrometer RDX. A mixture of water, isobutanol, a dispersant and RDX was filled into an unspecified mill, resulting in a minimum mean particle size of $310 \mathrm{~nm}$ and a crystallite size of about $65 \mathrm{~nm}$. Several milling issues were mentioned such as the yield of about $25 \%$ and the importance of the residence time and the drying step.

Liu et al. $[34,35]$ studied the effect of drying n-RDX and HMX samples under various conditions. They first obtained n-RDX in solution from a mixture of water, ethanol, isopropanol and RDX. The suspension was put in a bidirectional rotation mill for $6 \mathrm{~h}$. Just as Rednere experienced, the drying process is a critical step to obtain a nanogranular powder. They dried the RDX under different conditions: freeze drying and supercritical drying led to quite impressive results, with median diameters of $160 \mathrm{~nm}$ and $200 \mathrm{~nm}$, respectively from a solution containing an average particle size of $64 \mathrm{~nm}$. After RDX and HMX, CL-20 was successfully processed the same way resulting in a median diameter of $180 \mathrm{~nm}$, as determined by SEM [8]. For the three compounds, the nanopowders were found to be less sensitize than their micrometer-sized counterparts.

Spray drying is a less energy intensive RDX drying method studied by Patel et al. [36]. RDX and CL-20 were bead milled from water with the addition of isobutanol and poly(vinyl alcohol) (PVOH) to stabilize the colloid by dispersion and coating. Then, an unknown polymeric binder was added just before drying the slurry by spray drying. Mean particle diameters down to 400 and $200 \mathrm{~nm}$ have been measured by DLS for RDX- and CL-20-based composites, respectively, after milling. However, no particle size distribution (PSD) curve was provided nor was the dispersion of the results indicated. It has been noticed that for $200 \mathrm{~nm}$ particles of CL-20 the $\alpha$ phase is obtained. From the same research group, nanoscale CL-20:HMX has been prepared by bead milling an aqueous suspension of $\varepsilon$-CL-20 and $\beta$-HMX in a 2:1 stoichiometric ratio [37]. The progressive conversion of raw materials into the co-crystal is achieved after one hour, resulting in a particle diameter of less than $200 \mathrm{~nm}$. However, not much attention was paid to the drying effect of large-scale batches. SEM and XRD measurements were performed on a drop-dried material at room temperature, and it is likely that the drying of several grams of such molecular crystal will behave differently. Furthermore, the accuracy of the XRD technique does not allow one to conclude that a complete conversion into the co-crystal has occurred, but rather indicates that the percentage of $\varepsilon$-CL-20 and $\beta$-HMX is lower by approximately $10 \%$. The full quantification by Rietveld or full pattern matching methods would have been useful to follow the conversion with time.

\section{Dry production methods}

\section{Physical vapor deposition (PVD)}

In 2002, Frolov and Pivkina first reported on a vacuum condensation process for high energetic materials [38-40]. The vacuum deposition of ammonium nitrate (AN), RDX and a composite AN-RDX was performed on a cooled quartz substrate. The mean particle diameter was directly measured from atomic force microscopy (AFM): a diameter of $50 \mathrm{~nm}$ was obtained for the three materials, even after processing the nanopowder (removal from the quartz substrate and pressing into tablets).

Mil'chenko et al. [41] delved further in the physical vapor deposition (PVD) process with the deposition of 2,4,6-triamino1,3,5-trinitrobenzene (TATB), HMX, RDX, PETN and BTF as thin layers on several substrates such as plexiglas and copper while changing operative parameters. The critical thickness of the detonating layer is an order of magnitude lower; the sensitivity toward impact and friction is barely mentioned as being similar to the raw materials but the sensitivity to laser excitation has been substantially increased.

Therefore, the PVD technique is highly suitable for pyrotechnic integrated circuits or micro-electromechanical systems [42,43], whereas mass production of loose powder is not economically viable. 


\section{Electrospray}

Radacsi et al. [44] crystallized sub-micrometer RDX using an electrospray technique. A solution of RDX/acetone is sprayed through a nozzle that is electrically charged to a grounded plate. This charges the droplet surface, increasing the surface energy and thus triggering the fission into smaller droplets. This Coulomb fission phenomenon and the evaporation of the solvent leads to crystallization and the deposition of nonagglomerated particles. By adjusting the nozzle parameters and the potential difference various morphologies of RDX particles resulted. For instance, micrometer-sized hollow spheres of agglomerated RDX were produced. The minimum mean size was $400 \mathrm{~nm}$. This sub-micrometer RDX sample exhibited a clear insensitivity towards friction, but with the same impact sensitivity as conventional micrometer-sized RDX (Table 4).

\begin{tabular}{|c|c|c|}
\hline RDX & $\begin{array}{c}\text { Impact } \\
{[\mathrm{J}]}\end{array}$ & $\begin{array}{c}\text { Friction } \\
{[\mathrm{N}]}\end{array}$ \\
\hline conventional & 7.5 & 120 \\
\hline sub-micrometer & 10 & $>360$ \\
\hline
\end{tabular}

Reus et al. [45] then processed bicomponent systems: proteins and $\mathrm{RDX} / \mathrm{TNT}$. It is mentioned that the XRD patterns of the final products differ from that of the raw material, which seems to indicate either a strong degradation or cocrystallization. Infrared spectroscopy definitely demonstrated a critical partial decomposition of both RDX and TNT due to the electrospray technique and the same phenomenon has likely happened for Radacsi et al., too. Whatever was really obtained, Reus crystallized very small particles, estimated by us to be less than or approximately $100 \mathrm{~nm}$ for any initial ratio of TNT/RDX. AFM measurements could have provided much more information about the size and shape of such nanoparticles, especially since they are well dispersed on a substrate. The sensitivity tests have been performed on those degraded materials, which were found to be as insensitive as TNT.

The electrospray technique can be used to create a fine spray of micrometer-sized charged droplets repelling each other, which is ideal for crystallization. The high voltage needed is a major handicap for processing sensitive powders such as energetic materials containing nitro groups.

\section{Plasma}

During his Ph.D. project [46], Radacsi used an innovative and advanced technique to crystallize sub-micrometer RDX: a collison nebulizer that aerosolizes an RDX/acetone solution to a surface dielectric barrier discharge (SDBD) plate where a cold plasma disrupts the droplet by the Coulomb fission. Like the electrospray technique, each droplet should crystallize into a unique single crystal. The minimum mean diameter obtained was $500 \mathrm{~nm}$, with a diameter distribution from 200 to $900 \mathrm{~nm}$, and the particles had a prismatic or spherical shape. Again, like the sub-micrometer powder obtained from the electrospray technique, the $500 \mathrm{~nm}$ RDX was desensitized to friction but not to impact (Table 5).

\begin{tabular}{|c|c|c|}
\hline RDX & $\begin{array}{c}\text { Impact } \\
{[\mathrm{J}]}\end{array}$ & $\begin{array}{c}\text { Friction } \\
{[\mathrm{N}]}\end{array}$ \\
\hline conventional & 5 & 144 \\
\hline sub-micrometer & 5 & $>360$ \\
\hline
\end{tabular}

\section{Supercritical/gas antisolvent precipitation}

Supercritical antisolvent (SAS) precipitation uses the same principle as liquid crystallization, substituting the liquid antisolvent by a supercritical fluid. The very high diffusivity of supercritical fluids leads to a rapid supersaturation and thus to a sudden precipitation. Various approaches are used in SAS. One is the supercritical antisolvent (GAS) precipitation, where the liquid solution is first loaded into the vessel before the addition of the supercritical antisolvent. For $\mathrm{RDX}, \mathrm{CO}_{2}$ is an appropriate supercritical antisolvent. Gallagher et al. [47] first investigated the use of the GAS process for RDX in 1992. Supercritical $\mathrm{CO}_{2}$ injected into an $\mathrm{RDX} /$ cyclohexanone solution at various injection times, injection quantities and temperatures. In this first use of GAS for RDX, various particle sizes and morphologies were obtained, but none under the micrometer scale. Since then, several process derived from the GAS process (which could be referred as SAS subprocesses) have been used to form particles on the sub-micrometer and nanoscale for energetic materials. However, since 1992, no GAS/SAS process has been reported to produce energetic materials with a diameter less than a micrometer [48-51], except for 5-nitro-1,2,4-triazol-3one (NTO) by Lim et al. [52,53].

\section{Aerosol solvent extraction system (ASES) process}

The aerosol solvent extraction system (ASES) process involves precipitation through spraying the solution through an atomization nozzle into supercritical $\mathrm{CO}_{2}$. Lee et al. [51] used GAS and ASES systems to crystallize $\beta$-HMX. However, undesirables shapes (needle-like, irregular and aggregated) were produced by ASES at all operating conditions, whereas GAS led to regular shapes with the desired $\beta$-phase. Dou et al. [54] sprayed RDX dissolved in DMF to obtain micrometer-sized particles of high polydispersity. However, sub-micrometer-sized polymers and biopolymers produced by ASES have been reported since the 
1990s by Reverchon [55] and Dixon et al. [56]. Nevertheless, that technique can still be used on NC-based composites due to its polymer-like behavior.

\section{Solution-enhanced dispersion by supercritical fluid (SEDS)}

The solution-enhanced dispersion by supercritical fluid (SEDS) process was developed and patented by the Bradfort University to achieve a smaller droplet size compared to the previously described SAS methods. In the SEDS process, a solution with the solvated compound is sprayed into a supercritical antisolvent gas $\left(\mathrm{CO}_{2}\right.$ for RDX) through a nozzle with two coaxial passages. This technique can be seen as a specific implementation of the ASES process, where $\mathrm{CO}_{2}$ is introduced through the nozzle simultaneously with the solution. Shang and Zhang [57] produced spherical RDX particles with a mean particle diameter of $770 \mathrm{~nm}$ using SEDS, which finally resulted in the reduction of the particle size under to less than a micrometer.

\section{Particles from gas-saturated solutions (PGSS)}

Two patents $([58,59])$ first described a procedure that today is called particles from gas-saturated solutions (PGSS). The PGSS technique consists of dissolving a compressed gas into a solution of the substrate in a solvent, then passing it through a nozzle. The sudden decompression leads to crystallization and thus to the formation of solid particles. Although this method is widely used on a large scale with a wide range of products (from inorganic powder to pharmaceutical compounds [60]), nothing has been reported [49] concerning energetic materials processed by PGSS.

\section{Rapid expansion of supercritical solutions (RESS)}

The rapid expansion of supercritical solutions (RESS) concept was first described by Hannay and Hogart more than a century ago [61] but studied by Krukonis [62] and the Battelle Institute research team $[63,64]$ in more detail. The RESS process consists of spraying a supercritical (sc) fluid containing the substrate through a nozzle in a low pressure chamber ( $0-60$ bar). The sudden pressure decrease leads to rapid nucleation where small particles (from micrometer- to nanometer-sized) are finally collected. The use of a supercritical fluid like $\mathrm{CO}_{2}$ allows the direct production of a dry, pure powder. Teipel et al. $[48,65]$ first reported the use of RESS for energetic materials: $10 \mu \mathrm{m}$ diameter TNT particles were crystallized in those preliminary experiments. In this work, parameters which strongly influence the crystallization in a RESS apparatus were discussed: pressure, temperature, geometry of the nozzle and mass flow. Stepanov, a member of the research group of Krasnoperov, succeeded in the fine tuning of the RESS process to prepare dried n-RDX [66-69]. The formed n-RDX particles had a mean particle diameter ranging from 110 to $220 \mathrm{~nm}$ and an irregular spherical morphology. He performed a scale-up of the RESS process in order to increase the production capacity of RDX to $6 \mathrm{~g} / \mathrm{h}$ but with a $\mathrm{CO}_{2}$ consumption of $35 \mathrm{~kg} / \mathrm{h}$. Through RESS, a slight sensitization to impact and shock stimuli of the $200 \mathrm{~nm}$ RDX occurred compared to $500 \mathrm{~nm}$ RDX [6].

CL-20 has also been processed by RESS from trifluoromethane $\left(\mathrm{CHF}_{3}\right)$ [53]. Supercritical $\mathrm{CHF}_{3}$ has similar thermodynamic properties and is a better solvent of CL-20 than $\mathrm{scCO}_{2}$. Only micrometer-sized particles could be produced and no article reporting the results could be found. Changing the solvent is an area of research followed by Lee et al. [70] using compressed liquid dimethyl ether (DME) for RDX. The parametric study points out the role of inlet pressure and temperature and the nozzle diameter. The increase of any of those three parameters increases the particle size. Therefore, the two minimal mean particle sizes of 370 and $360 \mathrm{~nm}$ were obtained for the lowest mass flow rate of 0.37 and $0.85 \mathrm{~g} / \mathrm{s}$ of DME.

\section{Rapid expansion of supercritical solutions into an aqueous solution (RESS-AS) (or RESOLV)}

After the success of the RESS process, Essel et al. developed a new method based on that technique called RESS-AS, which as first reported in 2010 [71]. RESS-AS uses the versatility of the RESS process, while spraying into an aqueous solution containing a dispersant and/or growth inhibitor [72]. They reported [73] the synthesis of $30 \mathrm{~nm}$ RDX in a pH 7-stabilized solution. For such sizes and even at that $\mathrm{pH}$, agglomeration and Ostwald ripening occur. Therefore, to avoid the degradation of the nanoparticles, a polymer coating (PEI or poly(vinylpyrrolidone) (PVP)) is necessary. It should be mentioned that no subsequent sensitivity tests have been reported, provoking the question about whether a nanopowder could have be obtained from those colloidal suspensions.

\section{Laser ablation}

For the first time, Gottfried et al. [74] successfully produced RDX nanoparticles using laser ablation. A near-infrared, nanosecond pulsed laser was focused on military-grade RDX pellets. The scanning mobility particle sizer (SMPS) and SEM analyses showed a particle size distribution around $64 \mathrm{~nm}$ for a $200 \mathrm{~mJ}$ pulse and a $75 \mathrm{~mJ}$ pulse. No further analysis has been reported, such as trace decomposition, crystalline quality, apparent density, sensitivity, etc.

\section{Ultrasonic spray pyrolysis}

Since the nineties, spray crystallization and synthesis has been performed using several atomizers, and among them piezoelectric transducers $[75,76]$. As a spray technique, the goal is to produce one particle per droplet, but here the crystallization is controlled by the drying step, an oven just after the atomization. 
Spitzer et al. [77,78] and Kim et al. [79] both developed an apparatus to produce dried sub-micrometer RDX from an ultrasonic transducer. After the droplet generation, the solvent is evaporated by thermal gradient applied on the flux pulled by a pump. Highly agglomerated particles $200-500 \mathrm{~nm}$ were produced. Gao et al. $[19,80]$ used the same experimental setup while the previous works of Spitzer et al. and Kim et al. are never cited - with the exception of the furnace having here a gradient of temperature in order to produce $78 \mathrm{~nm}$ FOX7 particles and sub-micrometer-sized CL-20:HMX cocrystals. The claimed large-scale synthesis has not been fairly investigated. For instance increasing the number of piezoelectric transducers and scaling up the furnace would require excessive amounts of electrical power, thus making the cost-effectiveness of this method doubtful.

\section{Spray drying}

The development of spray drying $[81,82]$ has been expanding over the years and has recently become a suitable commercial solution at both R\&D and industry scales to produce dried particles from micrometers to nanometers. The pyrotechnic community quickly discerned the advantages of this simple technique to process energetic compounds as pure and composite materials.

The process sprays a solution containing a dissolved compound or particles in suspension into a hot gaseous stream (air or nitrogen) thus crystallizing into particles and/or drying the granules. van der Heijden et al. [83] showed that spray drying is able to crystallize finer RDX particles ("from $400 \mathrm{~nm}$ and larger") than their technique of precipitation into antisolvent ( 1 to $10 \mu \mathrm{m}$ ). Qiu et al. studied the crystallization of energetic compounds using spray drying with ultrasonic [84] or pneumatic [85] nozzles or with both type of nozzles [86]. All their experiments were done with the addition of poly(vinyl acetate) (PVAc) and resulted in micrometer-sized or sub-micrometer hollow spheres made of primary nanoparticles; the smallest of which were estimated at $20 \mathrm{~nm}$ for RDX/PVAc made from a pneumatic nozzle with a mean droplet size of around $7 \mu \mathrm{m}$. The versatility of the process allows the production of energetic composites (coating of TATB on micrometer-sized HMX, RDX or CL-20 by Ma et al. [87]), energetic/elastomer composites (micrometer-sized CL-20/EPDM by Ji et al. [88], micrometersized spheres of agglomerated HMX/Viton by Shi et al. [89]), and even co-crystals (micrometer-sized spheres of agglomerated HMX/TNT by Li et al. [90]).

\section{Spray flash evaporation (SFE)}

Risse and Spitzer developed an innovative process after experiencing the limitations of the ultrasonic spray pyrolysis method: beyond the inherent risk of using a high voltage electrostatic precipitator for energetic powders, the rate of evaporation of droplets was too low to avoid agglomeration and to crystallize sub-micrometer particles. Risse et al. [3,91] used the flashevaporation behavior of droplets to dramatically reduce the lifetime and the size of droplets. The compound is dissolved in a volatile solvent and that solution is heated just before being sprayed into vacuum, where the crystallization is triggered by the sudden temperature depression and the solvent evaporation. Due to the recent advances in that technique and its versatility, the spray flash evaporation (SFE) process deserves the following review of the corresponding literature.

\section{Theoretical insights on the SFE technology}

Flash evaporation is the physical phenomenon occurring when the boiling point of a liquid is lower than its actual temperature due to a sudden drop of pressure and/or a quick increase of temperature. The excess heat is instantly converted into latent heat of vaporization, cooling both liquid and vapor down to the saturation temperature. Multistage flash (MSF) evaporators of static water have been used since the middle of the 20th century [9294] with yield of around $100 \mathrm{~m}^{3}$ per day, receiving interest mainly from the U.S. West Coast [95] and Japan (national research program "seawater desalting and by product recovery" launched in 1969, [96]). Current applications are extended from solution concentration such as in wine industry [97] to heat dissipation of electronic chips and laser devices [98].

Brown and York [99] found a critical temperature above which the liquid jet burst by rapid bubbling. They injected water up to 13 bar through simple single-hole nozzles with a minimal diameter of $500 \mu \mathrm{m}$ into ambient pressure. The linear mean droplet size was found to follow a linear variation of temperature. Then, in 1981, Miyatake et al. were pioneers in the field of flash evaporation and published the first known articles about spray flash evaporation with superheating [100,101], after studying flash evaporation from water pool [102]. Many technical limitations restricted their studies for current issues: only straight-lined liquid jets were studied with basic optical techniques where the smallest drops and bubbles could not be indexed. However, Miyatake et al. [103] interestingly used electrolysis to generate more bubbles into a flashing water jet. Nowadays, not many laboratories still investigate flashing liquid jets. Guenther and Wirth [104] characterized flashing liquid jets with modern techniques and noticed the formation of bubbles inside a glass nozzle for high superheating. They also demonstrated that a simple acoustic measurement can be used to monitor the atomization of superheated liquids. The current application of flashing liquid jet is the improvement of MSF desalination processes of sea water $[105,106]$, where a much higher evaporation rate is obtained in contrast to static flash evaporation where the rate is surface dependent. 
We mentioned applicative publications for now, but specific studies on the flashing phenomenon of droplets are rare. Owen and Jalil [107] investigated that specific form of evaporation on isolated drops. A superheating of 0 to $5{ }^{\circ} \mathrm{C}$ triggers only surface evaporation, then boiling occurs at higher superheating. Flashing is triggered for superheating from 18 to $24{ }^{\circ} \mathrm{C}$ for a drop of $1-3 \mathrm{~mm}$ and larger drops flash more readily as illustrated in Figure 2. Since flash evaporation is closely related to cooling, many theoretical approaches start with a simplified model without superheating: Shin et al. [108] and Satoh et al. [109] thoroughly described the evaporation behavior of a water droplet in an abruptly evacuated atmosphere leading to its solidification. Sobac et al. [110] developed a comprehensive model of the evaporation of a liquid spherical drop that is not applicable to extremely small droplets as in flashing spray.

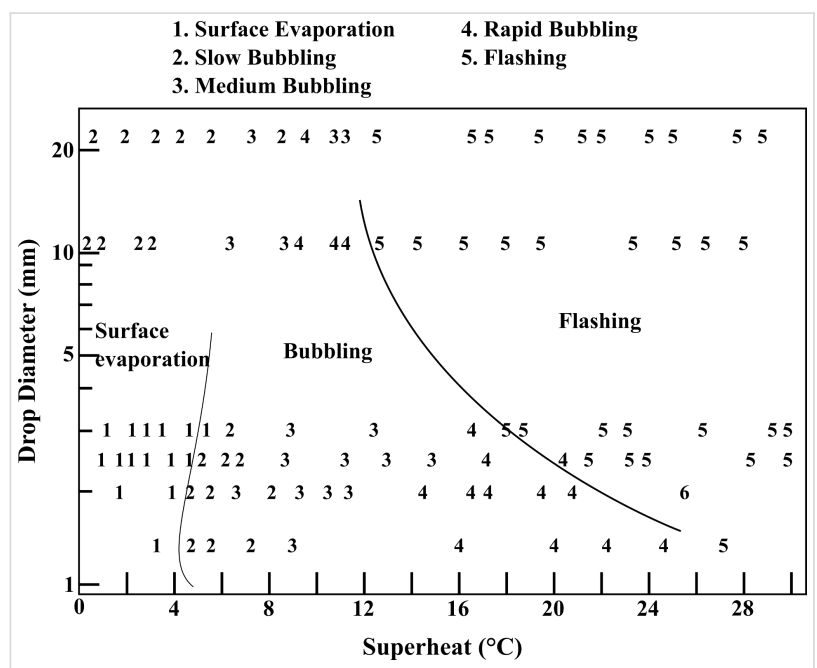

Figure 2: Empirical diagram of the evaporation of a water drop, adapted from [107]

Interesting studies close to the current SFE process came from Gebauer et al. [111-114]. In their system, a pressurized, super- heated liquid is atomized through an hollow cone nozzle into a low pressure chamber and micrometer-sized particles are recovered. However, only a partial evaporation occurs and leads to further crystal growth during the flight time and is deposited in the sump collected in the bottom of the crystallizer.

\section{Comprehensive description of SFE}

Figure 3 describes a standard SFE apparatus, where two zones can be distinguished: a high pressure one is in red and the low pressure one in blue. One storage tank (4) is used for technical operation such as preheating, postcooling and cleaning and is filled with technical grade solvent. The compounds of interest are dissolved in solvent in an other tank (1). Both tanks are pressurized with a dry carrier gas up the pre-expansion pressure. the fluid is brought inside the atomization chamber at this pressure using standard industrial hydraulic tubes; there, the liquid is superheated within a jacket around a metallic heat conductor. A regulation is made within a thermocouple (type $\mathrm{K}$, diameter $1.5 \mathrm{~mm}$ ) plugged to a proportional/integral/derivative (PID) controller and inserted in the the tubing. Details can be seen in Figure 4: the tip of the thermocouple measures the temperature after the heating jacket and just before the nozzle mounted on a full flow quick coupling. The superheated fluid is then sprayed through a hollow cone nozzle (3) into a chamber at a vacuum below 10 mbar.

Figure 5 illustrates the recovery system of the solid particles from the gaseous flow coming from the evaporation. The cyclonic separators are made from the description of Chen and Tsai [115] who calculated a cut-off diameter of 21.7-49.8 nm. A glass flat flange reaction vessel allows one to gather the powder easily. One cyclone separates the aerosol, while the other unit can be isolated from the vacuum to recover the product. In this way the process operates continuously, spraying and separating the aerosol at any flow rate. At the end, the flow of gaseous solvent passes through a $35 \mathrm{~m}^{3} / \mathrm{h}$ vacuum pump; a

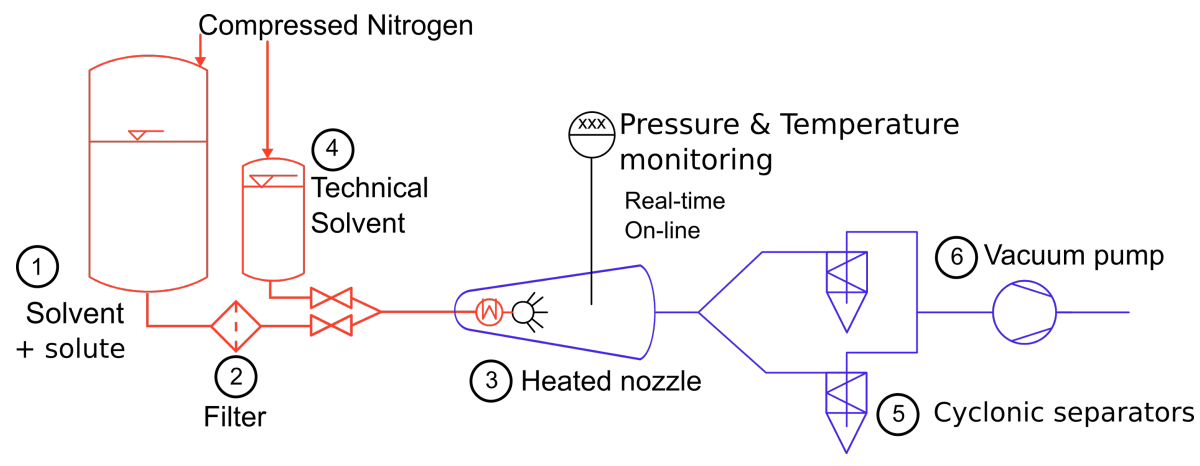

Figure 3: SFE installation as patented and used in this present work 


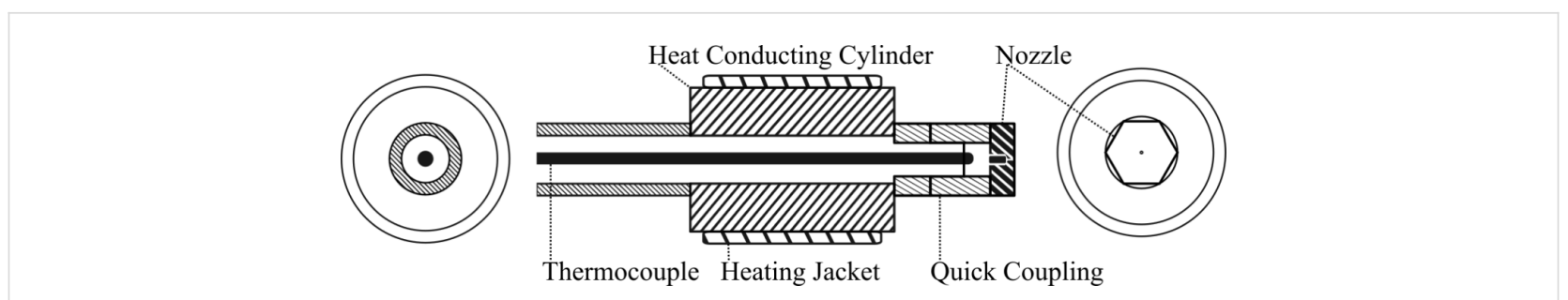

Figure 4: Schematic cross-sections of the nozzle and its heating system; from left to right, rear view, longitudinal cross-section and front view.

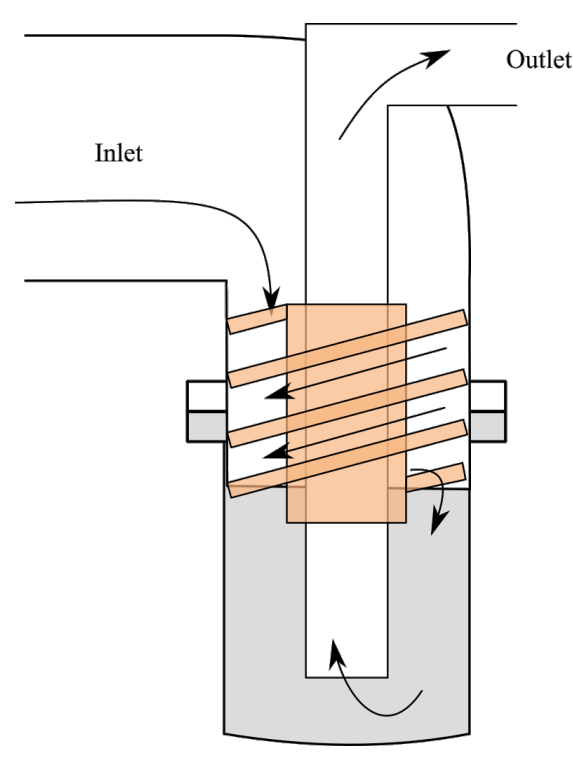

Figure 5: System for the product recovery: the cyclonic separator fo vacuum (orange) and the interchangeable vessel (grey).

condenser after the pump can recover the solvent for industrial installations. The standard operating conditions are: 40 bar of inlet pressure, $160{ }^{\circ} \mathrm{C}$ at the hollow cone nozzle, and an orifice diameter of $60 \mu \mathrm{m}$.

\section{Versatility of SFE}

The following parameters of SFE can be adapted, according to the solute and the desired particle size range:

- Type of solvent: The most suitable solvents for SFE are those having a low boiling point in the range of $30-70{ }^{\circ} \mathrm{C}$. A high molar heat capacity helps to stabilize the fluid in its superheated state.

- Superheating temperature: Higher superheating temperature increases the evaporation rate, as mentioned earlier. The superheating temperature depends on the mass flow, the heat exchanger (surface, geometry and residence time) and the fluid properties.
- Pre-expansion pressure: The pre-expansion pressure has to be above the vapor pressure of the superheated solvent. That pressure should also be compatible with nozzle diameter and type, with for instance an operating range from 30 to $150 \mathrm{bar}$ for sub-millimeter nozzles. The droplet size is also known to decrease at higher pressures. However a higher pressure involves a higher flow rate, and a degradation of the superheating.

- Saturation pressure and temperature: The vacuum pump specifications mainly dictate the saturation pressure and temperature of the spray cone in the atomization chamber. The volume and geometry of the chamber and the ones of the whole vacuum piping system have only a minor influence when reaching high pumping flow rate.

- Nozzle diameter: For most nozzles types like hollow cone nozzles, full cone nozzles, or flat jet nozzles, a reduced orifice diameter decreases the droplet size; it also increases the preexpansion pressure needed to guarantee a fine spraying.

Besides the innovative applications of energetic nanomaterials, such as the synthesis of ultrafine nanodiamonds [116,117] and reactivity enhancement [10], the versatility of SFE allows the crystallization at a sub-micrometer or nanometer scales of a wide range of organic compounds. In particular, cocrystals of medical materials are of interest for drug enhancement and were successfully processed through SFE at the nanoscale [118]. Inorganic nanoparticles were also produced on the nanoscale through SFE by Klaumuenzer et al. [119]. ZnO was crystallized from the precursor zinc acetate dihydrate dissolved in ethanol with addition of water. From early experiments, primary nanoparticles of $20 \mathrm{~nm}$ were found to be agglomerated in sub-size structures, whereas the slightly larger nanoparticles were found much less agglomerated using the classical wet method. However, the SFE clearly demonstrated the feasibility of faster and quite efficient crystallization of inorganic particles from precursors. Le Brize and Spitzer [120] processed energetic composite materials by SFE: a sub-micrometer structure was evidenced from SEM pictures and an higher degree of chemical interaction was also found from IR and Raman spectra. The high versatility of the SFE permits the processing of 
liquid (poly(ethylene glycol) (PEG) 400) and solid (PVP 40k) polymers to tune the RDX particle size distribution from the nanometer to the micrometer scale with controlled shapes [121] The smallest particle diameter obtained was at $160 \mathrm{~nm}$ with a spherical morphology. Adding $0.05 \mathrm{wt} \%$ of PVP decreased the size of RDX by $34 \%$, from around $500 \mathrm{~nm}$ to $320 \mathrm{~nm}$, but also significantly improved the spheric shape. Additionally, all the synthesized RDX samples were less sensitive, especially toward electrostatic discharge.

\section{Conclusion}

As displayed in Table 6, the smallest diameter of RDX is either obtained from wet techniques or from small-scale approaches which cannot be transferred to industry (PVD and laser ablation). Even if PVD has been successfully used in the semiconductor sector for our everyday electronic devices for decades, PVD applied on energetic materials will never be able to reach a production of several hundred of grams per hour. However, PVD is suitable for the current trend to create "pyrotechnic integrated circuits". Femtosecond laser ablation is used for nanoparticle synthesis of metal in solution at the laboratory scale. The colloids produced are found to be extremely stable. Used in dried conditions, a deposit of nanoparticles on a substrate could be obtained from a gas flow, or a dried powder could be collected within a cyclonic separator. This laser-based technique has been used to cut high energetic material quite safely [122] but nanoparticle production would be severely limited to high-added-value industrial applications due to low production rate and high operation cost. Besides those two aspects, neither methods would process advanced composites, with a binder for instance, or would be able to do concomitant or co-crystallization.
The production of nanoparticles through wet techniques has become a common industrial chemical process. The European project, Sustainable Hydrothermal Manufacturing of Nanometerials (SHYMAN), aims to increase the production rate of a continuous hydrothermal process from 1-10 tons/year to 100 tons/year for inorganic nanomaterials [123]. Tsuzuki et al. [124] statistically studied which methods for inorganic nanosynthesis are mostly employed in industry: vapor (39\% mainly chemical vapor deposition (CVD)) and liquid (45\%) phase synthesis are the two main types of techniques. Since patents or brand marketing can restrain the choice of a technology, this distribution should not be interpreted as a way to estimate the robustness or versatility of the methods. Considering such wide adoption of wet techniques [125] and the knowledge from chemical engineering (homogenization in large reactor, processing of liquid flow, versatility, safety etc.), wet crystallization methods are a logical choice to process organic materials. However, unlike inorganic and metal nanoparticles, organic matter is very sensitive to drying as we previously saw for milling. Yet this delicate step is required since the reactivity of high energetic materials is fully exploited in the dried state. Freeze drying and supercritical drying seem to kinetically and partially prevent crystal growth from occurring. Only a complete growth inhibition will lead to the production of smaller nanoparticles under $100 \mathrm{~nm}$ from milling or antisolvent/cooling crystallization. From an industrial point of view, freeze or supercritical drying are batch-only processes. All current industrial drying process are not designed to tackle the fast growth of soft matter. Innovative techniques such as spin freezing [126] or spray drying enhance the processability, and potentially the performance, but the rigorous testing of their reliability is yet an open issue.

\begin{tabular}{|c|c|c|c|c|c|c|}
\hline Process & Working pressure(s) & Heating $\left({ }^{\circ} \mathrm{C}\right)$ & Continuous & Scale-up & Limiting step(s) & Smallest size ${ }^{a}$ \\
\hline Sol-gel & atmospheric & no & no & -+ & matrix, drying & $100-150^{b}$ \\
\hline Antisolvent & atmospheric & 70 & could be & - & injection, drying & 38 \\
\hline Milling & atmospheric & cooling & no & + & drying & $160^{c}$ \\
\hline PVD & $10^{-4} \mathrm{~Pa}^{\mathrm{d}}$ & $100-200$ & no & -- & vacuum & 50 \\
\hline Electrospray & atmospheric & no & could be & - & mass flow, electric field & 400 \\
\hline ASES & $12 \mathrm{MPa}$ & yes and cooling & no & -- & $\mathrm{scCO}_{2}^{\mathrm{e}}$ & micrometers \\
\hline SEDS & $35 \mathrm{MPa}^{\mathrm{d}}$ & yes & no & -- & $\mathrm{scCO}_{2}$ & micrometers \\
\hline RESS & $35 \mathrm{MPa} \rightarrow 0.1-5 \mathrm{MPa}$ & yes and cooling & could be & -+ & $\mathrm{scCO}_{2}$ & 200 \\
\hline RESS-AS & $35 \mathrm{MPa} \rightarrow$ atmospheric & 25 & could be & -+ & $\mathrm{scCO}_{2}$, drying & $30^{f}$ \\
\hline Laser & atmospheric & no & no & - & mass flow & 64 \\
\hline Ultrasonic & atmospheric & $50-150$ & could be & -+ & transducer & $200-500$ \\
\hline Spray drying & atmospheric & $50-100$ & could be & ++ & evaporation ratio & 400 \\
\hline SFE & $5 \mathrm{MPa} \rightarrow 5 \mathrm{mbar}$ & 150 & yes & ++ & vacuum & 300 \\
\hline
\end{tabular}

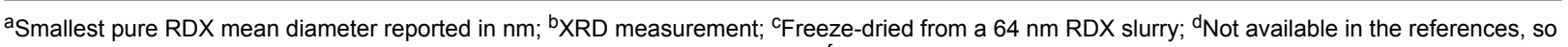
the value is based on usual operating conditions; ${ }^{\mathrm{e}}$ supercritical carbon dioxide; ${ }^{\mathrm{f}} \mathrm{From} \mathrm{DLS}$, no report about dried state. 
The ball milling techniques raise concerns about the purity of the product. It is well know that after such an extensive friction process, industrially milled ceramics cannot be used for high purity chemical processes [127]. Industry moved to other techniques such as vapor phase-based techniques to overcome that limitation in addition to others like the lake of control, local heating etc. Even with soft matter, similar issues can be expected; even small quantities of metallic impurities could catalyze the degradation of the explosive and/or sensitize it.

After 25 years of research and 10 years of process engineering, the supercritical fluid (SCF) technology has not convinced the industry and only marginal use for the specific commercial drug products have been reported [125]. First, the choice of the gas at industrial scales is returning to $\mathrm{CO}_{2}$ due to safety and affordability criteria. For instance, gases such as nitrous oxide or ethane have low critical values, but explosive mixtures can be generated. Trifluoromethane is inert, nonflammable and is usually a better solvent, but is significantly more expensive than $\mathrm{CO}_{2}$ and a potent greenhouse gas. Second, the main limitation, the solubility into $\mathrm{scCO}_{2}$, can be overcome by the addition of an organic cosolvent. Such a modification alters the environmentally safe nature of $\mathrm{scCO}_{2}$-based $\mathrm{SCF}$ and complicates the process by the need to remove any residual organic solvents. The aggregation phenomenon is commonly observed in SCF processes; further investigations on the role of different particle collection environments are needed, but RESS-AS processes greatly avoid the particle aggregation. The use of a liquid antisolvent with polymeric stabilizers has been found to be very effective. However, it compromises the recovery of a dry, pure powder, going back to square one with the drying issues previously discussed.

Spray techniques are commonly used in the industry, such as microencapsulation massively used for food $[128,129]$, spray drying in pulmonary drug delivery for production of uniform and breathable size particles [130] or even thermal spray deposition of metallic material [131]. Spraying is a method which allows easy implementation of an installation and easy direct control over the injection. However, because of the low technological cost of atomizing nozzles and the low control over the spray itself, details and know-how are much more important than for other processes. Direct spray drying as a crystallization technique for RDX does not produce sub-micrometersized particles without the help of an additive and the SCF techniques are not suitable for industry. The need for an intermediate method in terms of pressure and temperature leads to the creation of the SFE technique, especially tailored for crystallization. SFE operates from 40-100 bar with an RDX solubility in acetone around $5 \mathrm{wt} \%$, whereas $\mathrm{scCO}_{2}$ is formed from $74-500$ bar for a solubility from null to $0.025 \mathrm{wt} \%$.
The SFE technology has proven its high level of versatility and reliability, and is now entering advanced stages of development. Scale-up studies are performed and advanced in situ characterization is under investigation. Preliminary results using phase Doppler interferometry (PDA) reveals that SFE produces micrometer sized droplets with high velocities, typical features of interest for metastable crystalline structures.

For a deeper understanding of the crystallization of energetic materials at the nanoscale, a better comprehension of the resulting powder is needed. Beyond the issue of the reliability of the sensitivity values of energetic materials at the nanoscale [132] and tested at the laboratory scale [133], the pyrotechnic community should actively discuss the repeatability, the agglomeration of particles and the particle size distribution with accurate peak fittings.

\section{Supporting Information}

\section{Supporting Information File 1}

CSV data on fine energetic materials.

[http://www.beilstein-journals.org/bjnano/content/

supplementary/2190-4286-8-49-S1.csv]

\section{References}

1. Nouguez, B.; Eck, G. Propellants, Explos., Pyrotech. 2016, 41, 548-554. doi:10.1002/prep.201600031

2. Tarver, C. M.; Chidester, S. K.; Nichols, A. L., III. J. Phys. Chem. 1996, 100, 5794-5799. doi:10.1021/jp953123s

3. Risse, B. Continuous Crystallization of Ultra-Fine Energetic Particles by the Flash-Evaporation Process. Ph.D. Thesis, Universite de Lorraine, France, 2012.

4. Bayat, Y.; Zeynali, V. J. Energ. Mater. 2011, 29, 281-291. doi:10.1080/07370652.2010.527897

5. Klapötke, T. M. Chemistry of High-Energy Materials, 3rd ed.; De Gruyter: Berlin, Germany, 2015.

6. Stepanov, V.; Anglade, V.; Balas Hummers, W. A.; Bezmelnitsyn, A. V.; Krasnoperov, L. N. Propellants, Explos., Pyrotech. 2011, 36, 240-246. doi:10.1002/prep.201000114

7. Klaumünzer, M.; Pessina, F.; Spitzer, D. J. Energ. Mater. 2016, 1-10. doi:10.1080/07370652.2016.1199610

8. Liu, J.; Jiang, W.; Yang, Q.; Song, J.; Hao, G.-z.; Li, F.-s. Def. Technol. 2014, 10, 184-189. doi:10.1016/j.dt.2014.04.002

9. Zhang, X.; Weeks, B. L. J. Hazard. Mater. 2014, 268, 224-228. doi:10.1016/j.jhazmat.2014.01.019

10. Comet, M.; Martin, C.; Klaumünzer, M.; Schnell, F.; Spitzer, D. Appl. Phys. Lett. 2015, 107, 243108. doi:10.1063/1.4938139

11. Fedoroff, B. T.; Sheffield, O. E. Encyclopedia of Explosives and Related Items; Picatinny Arsenal Dover: Dover, NJ, U.S.A., 1966; Vol. 3.

12. Pant, A.; Nandi, A. K.; Newale, S. P.; Gajbhiye, V. P.; Prasanth, H.; Pandey, R. K. Cent. Eur. J. Energ. Mater. 2013, 10, 393-407. 
13. Chen, H.; Li, L.; Jin, S.; Chen, S.; Jiao, Q. Propellants, Explos., Pyrotech. 2012, 37, 77-82. doi:10.1002/prep.201000014

14. Hudson, R. J.; Moniruzzaman, M.; Gill, P. P. Propellants, Explos., Pyrotech. 2015, 40, 233-237. doi:10.1002/prep.201400129

15. Hudson, R. J. Investigating the Factors Influencing RDX Shock Sensitivity; Cranfield University: Cranfield, United Kingdom, 2012.

16. Kumar, R.; Siril, P. F.; Soni, P. Propellants, Explos., Pyrotech. 2014, 39, 383-389. doi:10.1002/prep.201300104

17. Kumar, R.; Siril, P. F.; Soni, P. J. Energ. Mater. 2015, 33, 277-287. doi:10.1080/07370652.2014.988774

18. Bayat, Y.; Zarandi, M.; Khadiv-Parsi, P.; Beni, A. S. Cent. Eur. J. Energ. Mater. 2015, 12, 459-472.

19. Gao, B.; Wu, P.; Huang, B.; Wang, J.; Qiao, Z.; Yang, G.; Nie, F. New J. Chem. 2014, 38, 2334. doi:10.1039/c3nj01053h

20. Luo, Q.; Pei, C.; Liu, G.; Ma, Y.; Li, Z. Nano 2015, 10, 1550033. doi:10.1142/S1793292015500332

21. Li, W.; Liao, N.; Duan, X.; Pei, C.; Zhou, X. Cryst. Res. Technol. 2015, 50, 505-515. doi:10.1002/crat.201400425

22. Dabin, L.; Dong, X.; Baochang, Z. Preparation of Nanometer RDX In-situ by Solvent Substitution Effect in Reverse Micelles. 26th International Pyrotechnics Seminar; 1999; pp 269-275.

23. Gash, A. E.; Simpson, R. L.; Tillotson, T. M.; Satcher, J. H.; Hrubesh, L. W. Making Nanostructured Pyrotechnics in a Beaker. 27th International Pyrotechnics Seminar; Grand Junction, CO, U.S.A., 2000.

24. Tillotson, T. M.; Fox, G. L.; Hrubesh, L. B.; Simpson, R. L.; Lee, K. W.; Swansiger, K. W.; Simpson, L. R. Sol-Gel Processing of Energetic Materials. 1997.

25. Tillotson, T. M.; Gash, A. E.; Simpson, R. L.; Hrubesh, L. W.; Satcher, J. H., Jr.; Poco, J. F. J. Non-Cryst. Solids 2001, 285, 338-345.

26. Rouquerol, J.; Avnir, D.; Fairbridge, C. W.; Everett, D. H.; Haynes, J. M.; Pernicone, N.; Ramsay, J. D. F.; Sing, K. S. W.; Unger, K. K. Pure Appl. Chem. 1994, 66, 1739-1758. doi:10.1351/pac199466081739

27. Guo, Q.-X.; Nie, F.-D.; Yang, G.-C.; Li, J.-S.; Chu, S.-J. Chin. J. Energ. Mater. 2006, 14, 268-271.

28. Wuillaume, A.; Beaucamp, A.; David-Quillot, F.; Eradès, C. Propellants, Explos., Pyrotech. 2014, 39, 390-396. doi:10.1002/prep.201400021

29. Li, G.; Liu, M.; Zhang, R.; Shen, L.; Liu, Y.; Luo, Y. Colloid Polym. Sci. 2015, 293, 2269-2279. doi:10.1007/s00396-015-3620-X

30. Jin, M.; Wang, G.; Deng, J.; Li, G.; Huang, M.; Luo, Y. J. Sol-Gel Sci. Technol. 2015, 76, 58-65. doi:10.1007/s10971-015-3750-0

31. Anniyappan, M.; Sonawane, S. H.; Shee, S. K.; Sikder, A. K. Cent. Eur. J. Energ. Mater. 2015, 12, 785-797.

32. Regulation (EC) No 1907/2006 of the European Parliament and of the Council; Registration, Evaluation, Authorisation and Restriction of Chemicals (REACH), 18 December 2006. http://data.europa.eu/eli/reg/2006/1907/2014-04-10

33. Redner, P.; Kapoor, D.; Patel, R.; Chung, M.; Martin, D. Production and Characterization of Nano-RDX; DTIC Document, 2006.

34. Liu, J.; Jiang, W.; Zeng, J.-b.; Yang, Q.; Wang, Y.-j.; Li, F.-s. Def. Technol. 2014, 10, 9-16. doi:10.1016/j.dt.2013.12.006

35. Liu, J.; Jiang, W.; Li, F.; Wang, L.; Zeng, J.; Li, Q.; Wang, Y.; Yang, Q. Propellants, Explos., Pyrotech. 2014, 39, 30-39. doi:10.1002/prep.201300050
36. Patel, R. B.; Stepanov, V.; Swaszek, S.; Surapaneni, A.; Quu, H. Propellants, Explos., Pyrotech. 2016, 41, 114-119. doi:10.1002/prep.201500130

37. Qiu, H.; Patel, R. B.; Damavarapu, R. S.; Stepanov, V. CrystEngComm 2015, 17, 4080-4083. doi:10.1039/C5CE00489F

38. Frolov, Y. V.; Pivkina, A. N.; Ul'yanova, P. A.; Zav'yalov, S. A. Combust., Explos. Shock Waves (Engl. Transl.) 2002, 38, 709-713.

39. Pivkina, A.; Ulyanova, P.; Frolov, Y.; Zavyalov, S.; Schoonman, J. Propellants, Explos., Pyrotech. 2004, 29, 39-48. doi:10.1002/prep.200400025

40. Frolov, Yu. V.; Pivkina, A. N.; Zav'yalov, S. A.; Murav'ev, N. V.; Skryleva, E. A.; Monogarov, K. A. Russ. J. Phys. Chem. B 2010, 4, 916-922. doi:10.1134/S1990793110060072

41. Mil'chenko, D. V.; Gubachev, V. A.; Andreevskikh, L. A.; Vakhmistrov, S. A.; Mikhailov, A. L.; Burnashov, V. A.; Khaldeev, E. V.; Pyatoikina, A. I.; Zhuravlev, S. S.; German, V. N. Combust., Explos. Shock Waves (Engl. Transl.) 2015, 51, 80-85.

42. Rossi, C.; Zhang, K.; Esteve, D.; Alphonse, P.; Tailhades, P.; Vahlas, C. J. Microelectromech. Syst. 2007, 16, 919-931. doi:10.1109/JMEMS.2007.893519

43. Piekiel, N. W.; Morris, C. J. ACS Appl. Mater. Interfaces 2015, 7, 9889-9897. doi:10.1021/acsami.5b01964

44. Radacsi, N.; Stankiewicz, A. I.; Creyghton, Y. L. M.; van der Heijden, A. E. D. M.; ter Horst, J. H. Chem. Eng. Technol. 2011, 34, 624-630. doi:10.1002/ceat.201000538

45. Reus, M. A.; Hoetmer, G.; van der Heijden, A. E. D. M.; ter Horst, J. H. Chem. Eng. Process. 2014, 80, 11-20. doi:10.1016/j.cep.2014.03.016

46. Radacsi, N. Process Intensification in Crystallization: Submicron Particle Generation Using Alternative Energy Forms. Ph.D. Thesis, Delft University of Technology, Delft, Netherlands, 2012.

47. Gallagher, P. M.; Coffey, M. P.; Krukonis, V. J.; Hillstrom, W. W. J. Supercrit. Fluids 1992, 5, 130-142. doi:10.1016/0896-8446(92)90030-N

48. Teipel, U.; Förter-Barth, U.; Gerber, P.; Krause, H. H. Propellants, Explos., Pyrotech. 1997, 22, 165-169. doi:10.1002/prep.19970220313

49. Jung, J.; Perrut, M. J. Supercrit. Fluids 2001, 20, 179-219. doi:10.1016/S0896-8446(01)00064-X

50. Lee, B.-M.; Jeong, J.-S.; Lee, Y.-H.; Lee, B.-C.; Kim, H.-S.; Kim, H.; Lee, Y.-W. Ind. Eng. Chem. Res. 2009, 48, 11162-11167. doi:10.1021/ie900448w

51. Lee, B.-M.; Kim, S.-J.; Lee, B.-C.; Kim, H.-S.; Kim, H.; Lee, Y.-W. Ind. Eng. Chem. Res. 2011, 50, 9107-9115. doi:10.1021/ie102593p

52. Lim, G. B.; Lee, S. Y.; Koo, K. K.; Park, B. S.; Kim, H. S. Gas Anti-Solvent Recrystallization of Molecular Explosives under Subcritical to Supercritical Conditions. Proceedings of the 5th Meeting on Supercritical Fluids; 1998.

53. Reverchon, E.; Kröber, H.; Teipel, U. Crystallization with Compressed Gases. Energetic Materials; Wiley-VCH: Weinheim, Germany, 2005; pp 159-182.

54. Dou, H.; Kim, K.-H.; Lee, B.-C.; Choe, J.; Kim, H.-S.; Lee, S. Powder Technol. 2013, 235, 814-822. doi:10.1016/j.powtec.2012.11.042

55. Reverchon, E. J. Supercrit. Fluids 1999, 15, 1-21. doi:10.1016/S0896-8446(98)00129-6

56. Dixon, D. J.; Johnston, K. P.; Bodmeier, R. A. AlChE J. 1993, 39, 127-139.

57. Shang, F.; Zhang, J. J. Energ. Mater. 2014, 32, S71-S82. doi:10.1080/07370652.2013.829133 
58. Best, W.; Mueller, F.-J.; Schmieder, K.; Frank, R.; Paust, J. Finely dispersed carotenoid pigments prodn. - by dissolving carotenoid in a supercritical gas, pref. carbon di:oxide, and dispersing the soln. in an aq. colloidal matrix. German Patent DE2943267 A1, Oct 26, 1981.

59. Graser, F.; Wickenhaeuser, G. Conditioning of Finely Divided Crude Organic Pigments. U.S. Patent US4451654 A, May 29, 1984.

60. Pourmortazavi, S. M.; Hajimirsadeghi, S. S. Ind. Eng. Chem. Res. 2005, 44, 6523-6533. doi:10.1021/ie0503242

61. Hannay, J. B.; Hogarth, J. Proc. R. Soc. London 1879, 30, 178-188. doi:10.1098/rspl.1879.0104

62. Krukonis, V. Supercritical Fluid Nucleation of Difficultto-Comminute Solids. Annual Meeting - American Institute of Chemical Engineers; 1984.

63. Matson, D. W.; Petersen, R. C.; Smith, R. D. J. Mater. Sci. 1987, 22, 1919-1928. doi:10.1007/BF01132917

64. Matson, D.; Fulton, J.; Petersen, R.; Smith, R. Ind. Eng. Chem. Res. 1987, 26, 2298-2306.

65. Teipel, U.; Kröber, H.; Krause, H. H. Propellants, Explos., Pyrotech. 2001, 26, 168-173. doi:10.1002/1521-4087(200110)26:4<168::AID-PREP168>3.0.CO;2-X

66. Stepanov, V. Production of Nanocrystalline Nitramine Energetic Materials by Rapid Expansion of Supercritical Solutions. M.S. Thesis, New Jersey Institute of Technology, 2003.

67. Stepanov, V.; Krasnoperov, L. N.; Elkina, I. B.; Zhang, X. Propellants, Explos., Pyrotech. 2005, 30, 178-183. doi:10.1002/prep.200500002

68. Stepanov, V.; Anglade, V.; Bezmelnitsyn, A.; Krasnoperov, L. N. Production and Characterization of Nanocrystalline Explosive RDX. AIChE Annual Meeting, San Francisco, CA, U.S.A.; 2006.

69. Stepanov, V. Production of nanocrystalline RDX by RESS: development and material characterization. Ph.D. Thesis, New Jersey Institute of Technology, 2008.

70. Lee, B.-M.; Kim, D. S.; Lee, Y.-H.; Lee, B.-C.; Kim, H.-S.; Kim, H.; Lee, Y.-W. J. Supercrit. Fluids 2011, 57, 251-258. doi:10.1016/j.supflu.2011.03.008

71. Essel, J. T.; Cortopassi, A. C.; Kuo, K. K.; Adair, J. H.; Leh, C. G.; Klapoetke, T. M. Synthesis of Energetic Materials by Rapid Expansion of a Supercritical Solution into Aqueous Solution (RESS-AS) Process; DTIC Document, 2010.

72. Essel, J. Processing Energetic Materials with Supercritical Fluid Precipitation Techniques. Ph.D. Thesis, Pennsylvania State University, 2012.

73. Essel, J. T.; Cortopassi, A. C.; Kuo, K. K.; Leh, C. G.; Adair, J. H. Propellants, Explos., Pyrotech. 2012, 37, 699-706. doi:10.1002/prep.201100139

74. Gottfried, J. L.; De Lucia, F. C., Jr.; Piraino, S. M. Characterization of the Morphology of RDX Particles Formed by Laser Ablation; U.S. Army Research Lab, Aberdeen Proving Ground, MD, Weapons and Materials Research Directorate, 2012. http://www.dtic.mil/cgi-bin/GetTRDoc?Location=U2\&doc=GetTRDoc.p df\&AD=ADA562280

75. Okuyama, K.; Wuled Lenggoro, I. Chem. Eng. Sci. 2003, 58, 537-547. doi:10.1016/S0009-2509(02)00578-X

76. Messing, G. L.; Zhang, S.-C.; Jayanthi, G. V. J. Am. Ceram. Soc. 1993, 76, 2707-2726. doi:10.1111/j.1151-2916.1993.tb04007.x

77. Spitzer, D.; Baras, C.; Schäfer, M. R.; Ciszek, F.; Siegert, B. Propellants, Explos., Pyrotech. 2011, 36, 65-74. doi:10.1002/prep.200900002
78. Spitzer, D.; Comet, M.; Baras, C.; Pichot, V.; Piazzon, N. J. Phys. Chem. Solids 2010, 71, 100-108. doi:10.1016/j.jpcs.2009.09.010

79. Kim, J.-W.; Shin, M.-S.; Kim, J.-K.; Kim, H.-S.; Koo, K.-K. Ind. Eng. Chem. Res. 2011, 50, 12186-12193. doi:10.1021/ie201314r

80. Gao, B.; Wang, D.; Zhang, J.; Hu, Y.; Shen, J.; Wang, J.; Huang, B.; Qiao, Z.; Huang, H.; Nie, F.; Yang, G. J. Mater. Chem. A 2014, 2, 19969-19974. doi:10.1039/C4TA04979A

81. Stein, W. A. Chem. Ing. Tech. 1973, 45, 906-907. doi:10.1002/cite.330451311

82. Broadhead, J.; Rouan, S. K. E.; Rhodes, C. T. Drug Dev. Ind. Pharm. 1992, 18, 1169-1206. doi:10.3109/03639049209046327

83. van der Heijden, A. E. D. M.; Creyghton, Y. L. M.; Marino, E.; Bouma, R. H. B.; Scholtes, G. J. H. G.; Duvalois, W.; Roelands, M. C. P. M. Propellants, Explos., Pyrotech. 2008, 33, 25-32. doi:10.1002/prep.200800204

84. Qiu, H.; Stepanov, V.; Di Stasio, A. R.; Chou, T.; Lee, W. Y. J. Hazard. Mater. 2011, 185, 489-493. doi:10.1016/j.jhazmat.2010.09.058

85. Qiu, H.; Stepanov, V.; Chou, T.; Surapaneni, A.; Di Stasio, A. R.; Lee, W. Y. Powder Technol. 2012, 226, 235-238. doi:10.1016/j.powtec.2012.04.053

86. Qiu, H.; Stepanov, V.; Di Stasio, A. R.; Surapaneni, A.; Lee, W. Y. Powder Technol. 2015, 274, 333-337. doi:10.1016/j.powtec.2015.01.032

87. Ma, Z.; Gao, B.; Wu, P.; Shi, J.; Qiao, Z.; Yang, Z.; Yang, G.; Huang, B.; Nie, F. RSC Adv. 2015, 5, 21042-21049. doi:10.1039/C4RA16527F

88. Ji, W.; Li, X.; Wang, J. Cent. Eur. J. Energ. Mater. 2015, 12, 831-840.

89. Shi, X.; Wang, C.; Wang, J.; Li, X.; An, C.; Wang, J.; Ji, W. Cent. Eur. J. Energ. Mater. 2015, 12, 487-495.

90. Li, H.; An, C.; Guo, W.; Geng, X.; Wang, J.; Xu, W. Propellants, Explos., Pyrotech. 2015, 40, 652-658. doi:10.1002/prep.201400175

91. Risse, B.; Spitzer, D.; Hassler, D.; Schnell, F.; Comet, M.; Pichot, V.; Muhr, H. Chem. Eng. J. 2012, 203, 158-165. doi:10.1016/j.cej.2012.07.032

92. Edwin, B. Flash-type distillation system. U.S. Pat. Appl. 2,908,618, Oct 13, 1959.

93. Porter, W. E.; Smith, B. F. Combined flash and vapor compression evaporator. U.S. Pat. Appl. 2,759,882, Aug 21, 1956.

94. Allen, E.; Hanson, K. Method of and apparatus for flash evaporation treatment. U.S. Pat. Appl. 2,803,589, Aug 20, 1957.

95. Desalting - State of the Art, Bulletin No. 134-69; Department of Water Resources, State of California, 1969.

96. Sawa, T.; Izumi, K.; Takahashi, S. Desalination 1976, 19, 369-380. doi:10.1016/S0011-9164(00)88045-5

97. Sebastian, P.; Nadeau, J. P. Int. J. Therm. Sci. 2002, 41, 269-280. doi:10.1016/S1290-0729(01)01315-1

98. Cheng, W.-L.; Zhang, W.-W.; Chen, H.; Hu, L. Renewable Sustainable Energy Rev. 2016, 55, 614-628. doi:10.1016/j.rser.2015.11.014

99. Brown, R.; York, J. L. AIChE J. 1962, 8, 149-153. doi:10.1002/aic.690080204

100. Miyatake, O.; Tomimura, T.; Ide, Y.; Fujii, T. Desalination 1981, 36, 113-128. doi:10.1016/S0011-9164(00)88635-X

101. Miyatake, O.; Tomimura, T.; Ide, Y.; Yuda, M.; Fujii, T. Desalination 1981, 37, 351-366. doi:10.1016/S0011-9164(00)88658-0 
102. Miyatake, O.; Murakami, K.; Kawata, Y.; Fujii, T. Bull. Soc. Sea Water Sci., Jpn. 1972, 26, 189-198. doi:10.11457/swsj1965.26.189

103. Miyatake, O.; Tomimura, T.; Ide, Y. J. Sol. Energy Eng. 1985, 107, 176-182. doi:10.1115/1.3267673

104.Günther, A.; Wirth, K.-E. Int. J. Heat Mass Transfer 2013, 64, 952-965. doi:10.1016/j.ijheatmasstransfer.2013.05.034

105. Miyatake, O.; Koito, Y.; Tagawa, K.; Maruta, Y. Desalination 2001, 137, 157-166. doi:10.1016/S0011-9164(01)00214-4

106. Ikegami, Y.; Sasaki, H.; Gouda, T.; Uehara, H. Desalination 2006, 194, 81-89. doi:10.1016/j.desal.2005.10.026

107. Owen, I.; Jalil, J. M. Int. J. Multiphase Flow 1991, 17, 653-660. doi:10.1016/0301-9322(91)90030-7

108.Shin, H. T.; Lee, Y. P.; Jurng, J. Appl. Therm. Eng. 2000, 20, 439-454. doi:10.1016/S1359-4311(99)00035-6

109.Satoh, I.; Fushinobu, K.; Hashimoto, Y. Int. J. Refrig. 2002, 25 , 226-234. doi:10.1016/S0140-7007(01)00083-4

110.Sobac, B.; Talbot, P.; Haut, B.; Rednikov, A.; Colinet, P. J. Colloid Interface Sci. 2015, 438, 306-317. doi:10.1016/j.jcis.2014.09.036

111.Gebauer, J.; Kaiser, R.; Kind, M. Chem. Ing. Tech. 2012, 84, 1901-1910. doi:10.1002/cite.201200021

112. Gebauer, J.; Kind, M. Chem. Eng. Process. 2015, 91, 130-140. doi:10.1016/j.cep.2015.03.012

113. Gebauer, J.; Kind, M. Chem. Eng. Sci. 2015, 133, 75-81. doi:10.1016/j.ces.2014.12.034

114.Gebauer, J.; Selzer, D.; Kind, M. Chem. Ing. Tech. 2016, 88, 881-889. doi:10.1002/cite.201500148

115.Chen, S.-C.; Tsai, C.-J. J. Nanopart. Res. 2007, 9, 71-83. doi:10.1007/s11051-006-9152-Z

116.Pichot, V.; Risse, B.; Schnell, F.; Mory, J.; Spitzer, D. Sci. Rep. 2013, 3, 2159. doi:10.1038/srep02159

117.Pichot, V.; Comet, M.; Risse, B.; Spitzer, D. Diamond Relat. Mater. 2015, 54, 59-63. doi:10.1016/j.diamond.2014.09.013

118.Spitzer, D.; Risse, B.; Schnell, F.; Pichot, V.; Klaumünzer, M.; Schaefer, M. R. Sci. Rep. 2014, 4, 6575. doi:10.1038/srep06575

119.Klaumünzer, M.; Schlur, L.; Schnell, F.; Spitzer, D. Chem. Eng. Technol. 2015, 38, 1477-1484. doi:10.1002/ceat.201500053

120.Le Brize, A.; Spitzer, D. Cent. Eur. J. Energ. Mater. 2016, 13, 547-556. doi:10.22211/cejem/64956

121.Pessina, F.; Schnell, F.; Spitzer, D. Chem. Eng. J. 2016, 291, 12-19. doi:10.1016/j.cej.2016.01.083

122.Roeske, F.; Benterou, J.; Lee, R.; Roos, E. Propellants, Explos., Pyrotech. 2003, 28, 53-57. doi:10.1002/prep.200390008

123. Charitidis, C. A.; Georgiou, P.; Koklioti, M. A.; Trompeta, A.-F.; Markakis, V. Manuf. Rev. 2014, 1, 11. doi:10.1051/mfreview/2014009

124. Tsuzuki, T. Nanotechnology Commercialization; CRC Press: Boca Raton, FL, U.S.A., 2013.

125.Sheth, P.; Sandhu, H.; Singhal, D.; Malick, W.; Shah, N.; Serpil Kislalioglu, M. Curr. Drug Delivery 2012, 9, 269-284. doi:10.2174/156720112800389052

126.De Meyer, L.; Van Bockstal, P.-J.; Corver, J.; Vervaet, C.; Remon, J. P.; De Beer, T. Int. J. Pharm. 2015, 496, 75-85. doi:10.1016/j.jpharm.2015.05.025

127. Carter, C. B.; Norton, M. G. Ceramic Materials; Springer: New York, NY, U.S.A., 2013.
128. Madene, A.; Jacquot, M.; Scher, J.; Desobry, S. Int. J. Food Sci. Technol. 2006, 41, 1-21. doi:10.1111/j.1365-2621.2005.00980.x

129. Gibbs, B. F.; Kermasha, S.; Alli, I.; Mulligana, C. N. Int. J. Food Sci. Nutr. 1999, 50, 213-224. doi:10.1080/096374899101256

130. Patel, B. B.; Patel, J. K.; Chakraborty, S. Recent Pat. Drug Delivery Formulation 2014, 8, 63-78. doi:10.2174/1872211308666140211122012

131.Lavernia, E. J.; Srivatsan, T. S. J. Mater. Sci. 2010, 45, 287-325. doi:10.1007/s10853-009-3995-5

132.Radacsi, N.; Bouma, R. H. B.; Krabbendam-la Haye, E. L. M.; ter Horst, J. H.; Stankiewicz, A. I.; van der Heijden, A. E. D. M. Propellants, Explos., Pyrotech. 2013, 38, 761-769. doi:10.1002/prep.201200189

133. Brown, G. W.; Sandstrom, M. M.; Preston, D. N.; Pollard, C. J.; Warner, K. F.; Sorensen, D. N.; Remmers, D. L.; Phillips, J. J.; Shelley, T. J.; Reyes, J. A.; Hsu, P. C.; Reynolds, J. G. Propellants, Explos., Pyrotech. 2015, 40, 221-232. doi:10.1002/prep.201400191

\section{License and Terms}

This is an Open Access article under the terms of the Creative Commons Attribution License (http://creativecommons.org/licenses/by/4.0), which permits unrestricted use, distribution, and reproduction in any medium, provided the original work is properly cited.

The license is subject to the Beilstein Journal of

Nanotechnology terms and conditions:

(http://www.beilstein-journals.org/bjnano)

The definitive version of this article is the electronic one which can be found at: doi:10.3762/bjnano.8.49 